J. Dairy Sci. 104:2463-2463

https://doi.org/10.3168/jds.2021-104-2-2463

๑ 2021 American Dairy Science Association ${ }^{\circledR}$. Published by Elsevier Inc. and Fass Inc. All rights reserved.

\title{
Corrigendum to "Effects of physical forms of starter and milk allowance on growth performance, ruminal fermentation, and blood metabolites of Holstein dairy calves" (J. Dairy Sci. 103:11300-11313)
}

A. Jafari, A. Azarfar, G. R. Ghorbani, M. Mirzaei, M. A. Khan, H. Omidi-Mirzaei, A. Pakdel, and M. H. Ghaffari

The affiliation for author A. Pakdel was shown incorrectly on the title page (page 11300). Dr. Pakdel's affiliation is Department of Animal Science, College of Agriculture, Isfahan University of Technology, Isfahan, Iran, PO Box 84156-83111.

The authors regret the error.

\section{REFERENCES}

Jafari, A., A. Azarfar, G. R. Ghorbani, M. Mirzaei, M. A. Khan, H. Omidi-Mirzaei, A. Pakdel, and M. H. Ghaffari. 2020. Effects of physical forms of starter and milk allowance on growth performance, ruminal fermentation, and blood metabolites of Holstein dairy calves. J. Dairy Sci. 103(12):11300-11313. https://doi.org/10.3168/jds.2020-18252. 